\title{
Site-specific analysis of deformation patterns on archaeological heritage by satellite radar interferometry
}

\author{
Deodato Tapete ${ }^{1}$ and Francesca Cigna ${ }^{2}$ \\ ${ }^{1}$ Department of Earth Sciences, University of Firenze, Via G. La Pira 4, I-50121, Firenze, Italy \\ ${ }^{2}$ British Geological Survey, Nicker Hill, Keyworth, NG12 5GG Nottingham, UK
}

\begin{abstract}
Exploitation of satellite radar interferometry on huge cultural heritage sites can facilitate the recognition of spatially distributed deformation patterns, whose morphology, jointly with the analysis of displacement time series, could clarify the nature of ongoing deterioration phenomena threatening the conservation of exposed archaeological heritage. Radar-interpretation is used on selected case studies located in Southern Italy to demonstrate the feasibility of Persistent Scatterers (PS) analyses for site-specific detection of superficial deformation, correlated to natural and/or human-induced instability processes. Evidence of subsidence for the radar targets identified within the archaeological area of Capo Colonna, Central Calabria, confirms the susceptibility of the entire promontory to ground instability, with potential effects on the ruins. Similarly, the uplift/subsidence patterns on the monumental area of Pozzuoli, W of Naples, testify the exposure of the geologic substratum underneath the archaeological structures to the active dynamics of the Campi Flegrei volcanic complex. Finally, the satellite analysis on the Valley of the Temples in Agrigento, Sicily, exemplifies the capability to distinguish differential displacement trends and seasonal variations within single PS time series.
\end{abstract}

\section{INTRODUCTION}

On site preservation of cultural heritage can benefit from the exploitation of remote sensing techniques which can support the identification of sectors and monuments affected by conservation criticalities due to ongoing instability processes. Such preventive diagnosis, extended over huge areas of investigation, can help the planning of necessary restorations, following a priority criterion based on a deeper and updated knowledge about the condition of the built heritage. Recent experimentations $[1,2]$ have demonstrated the promising potentials of Synthetic Aperture Radar Interferometry (InSAR) techniques for monitoring activities at different scales, i.e. 'single monument scale' and 'entire site scale', respectively, by means of ground-based and satellite configurations. The latter is highly suitable for wide-area monitoring, allowing the detection of Earth's surface changes [3], as well as natural and/or human-induced phenomena. An interesting example is offered by the displacements observed on structures and infrastructure within the urban contexts of some cities in Central Mexico and in the historic centre of the UNESCO site of Morelia, due to subsidence accelerated by groundwater overexploitation and influenced by past tectonic activity [4].

Based on site-specific analyses of satellite InSAR data available for selected archaeological sites located in Southern Italy, the paper attempts to demonstrate the usefulness of these techniques for recognition of deformation patterns which can be correlated to active deterioration processes of the structures and/or the geological substratum. The detailed analysis of deformation time series, obtained for the investigated case studies, provides a representative sample of the displacement trends which can be frequently found through InSAR data. 


\section{THEORY AND EXPERIMENTAL DETAILS}

The remote sensing data tested in this work are obtained from a multi-interferogram analysis of huge archives of multi-temporal images, acquired from satellite radar sensors and processed following the principle of Synthetic Aperture Radar (SAR) [5]. Wide spatial coverage allows 'entire site scale' analyses to be performed on areas up to hundreds or even thousands of square kilometers, with a meter resolution on the ground.

Processing of these data with Persistent Scatterer Interferometry (PSI) leads to the detection of superficial deformation of soil and/or structures thanks to the recognition, within the processed SAR images, of reflective targets distributed on the ground, which backscatter the microwave wavelengths sent from the satellite sensors. Such reflectors act as Persistent Scatterers (PS), as they maintain their dielectric properties almost constant during the monitoring period. PS correspond to either natural or artificial elements, such as rock outcrops, boulders, buildings, infrastructure, as well as monuments, columns and archaeological ruins that stick out of the ground. Conversely, vegetated areas provide low densities or, even, absence of targets.

Displacements $(\Delta \mathrm{d})$ occurred on a single PS in the period between two different acquisitions $(\Delta \mathrm{t})$ are recorded at the date of satellite observation along the LOS (Line Of Sight) direction and plotted vs. time, to retrieve the graph of the displacement trend over the monitoring period ( $P S$ deformation time series). The measurement along the LOS, with millimeter precision on single measure, implies that each displacement value corresponds to the LOS component of the real displacement vector associated to the detected superficial deformation. The magnitude and the direction of the LOS component depend on typology and geometric configuration of the deformation affecting the observed PS, as well as on the geometry of the satellite observation, while moving along its ascending (i.e. from $\mathrm{S}$ to $\mathrm{N}$ ) or descending orbit. Displacements away from the satellite result in negative values of LOS velocity (figure 1A-B); on the contrary, movements towards the satellite are expressed as positive values (figure $1 \mathrm{C}-\mathrm{D}$ ).

Among the deterioration processes on cultural heritage that can be detected by means of PSI, we can mention: toppling and collapses of wall masonries and columns due to instability of the geologic substratum, landslides and slope dynamics (figure 1A) or caused by natural and/or anthropogenic subsidence (figure 1B). Similarly, positive values of deformation rates may result from uplift movements due to ground expansion, clayey soil swelling, groundwater recharging, and/or toppling in the direction towards the satellite (figure 1C).

The temporal frequency with which a certain satellite observes the same area on the ground, determines the range of detectable phenomena, particularly in terms of kinetics. Shorter revisiting time generally allows more rapid processes to be monitored. The monthly sampling frequency of the radar satellites and the related periods analyzed for the case studies discussed in this paper (see table I) have configured a 'back monitoring' activity with temporal reconstruction of past/recent deformation, facilitating up-to-date detection of patterns and trends associable to recent/ongoing local instability.

After a preliminary evaluation of the feasibility of PSI analyses on cultural heritage contexts, site-specific analyses were performed on three different archaeological sites located in Southern Italy: Capo Colonna (Central Calabria), Pozzuoli (Campania Region) and the Valley of the Temples in Agrigento (Sicily). The exploited PS data were derived from the free access database of the Extraordinary Plan of Environmental Remote Sensing (EPRS-E), created by the Italian Ministry of Environment, Territory and Sea (METS), providing satellite displacement measurements with national coverage, available for administrative and scientific purposes. 
ENVISAT images, acquired with wavelength $(\lambda)$ of $5.63 \mathrm{~cm}$ and nominal revisiting time of 35 days, were processed with the PSP-DIFSAR approach (Persistent Scatterers Pairs -

DIFferential InSAR [6]), while ERS1/2 images, acquired with $\lambda=5.66 \mathrm{~cm}$ and the same nominal revisiting time as ENVISAT satellite, were processed with the PSInSAR technique (Permanent Scatterers InSAR [7]). Table I summarizes all technical information for each case study.

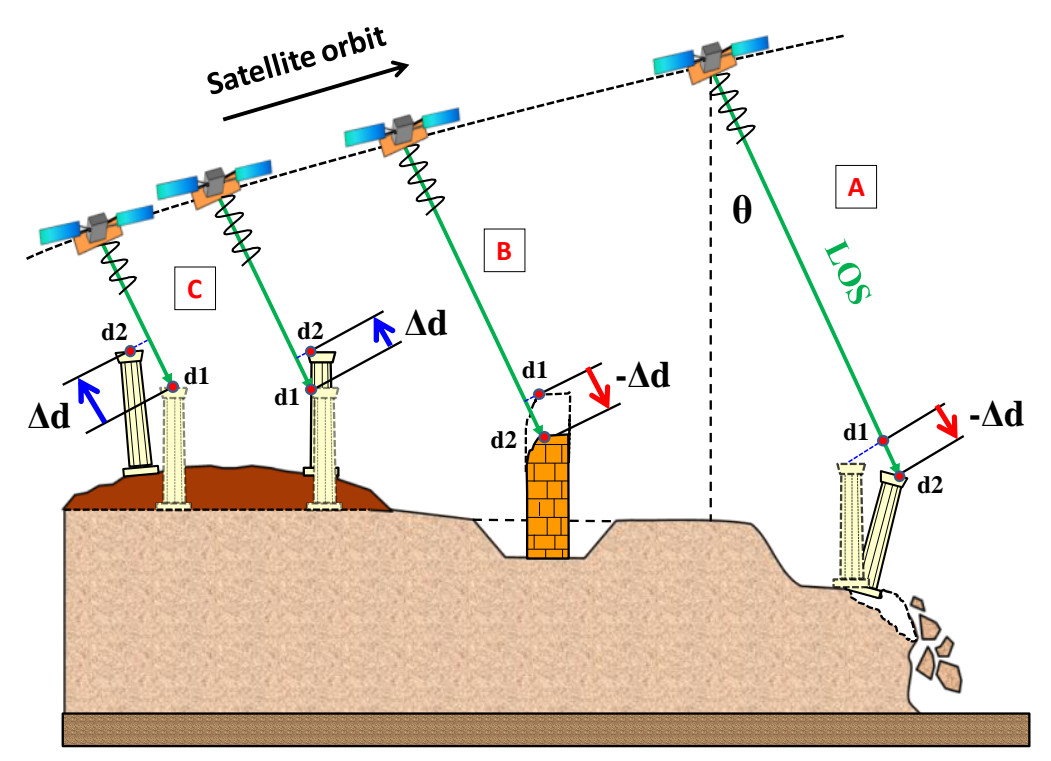

Figure 1. PSI detection of displacements $(\Delta d)$ occurred on monuments between two consecutive acquisitions. Changes of PS positions (from d1 to d2) are measured along the satellite LOS (tilted from the vertical of a look angle, $\theta$ ), identifying displacements away from the sensor (negative values; red arrows) due to: A) toppling; B) collapses caused by substratum instability, subsidence, earthquakes. Uplift movements due to ground expansion, clayey soil swelling and/or toppling towards the satellite (C), imply positive values of LOS deformation rates (blue arrows).

Table I Summary of PSI data stacks analyzed for the case studies, with distinction of satellites exploited and related acquisition geometry (ascending $=\mathrm{A}$; descending $=\mathrm{D}$ ).

\begin{tabular}{|c|c|c|c|}
\hline Site & Satellite & Geometry & Monitoring period \\
\hline \multirow{3}{*}{ Capo Colonna } & ERS1/2 & A & $27 / 03 / 1995-17 / 10 / 2000$ \\
\cline { 2 - 4 } & ERS1/2 & D & $18 / 06 / 1992-17 / 12 / 2000$ \\
\cline { 2 - 4 } & ENVISAT & A & $24 / 06 / 2003-27 / 07 / 2010$ \\
\hline \multirow{3}{*}{ Pozzuoli } & ERS1/2 & D & $08 / 06 / 1992-07 / 12 / 2000$ \\
\cline { 2 - 4 } & ENVISAT & A & $13 / 11 / 2002-22 / 10 / 2008$ \\
\hline \multirow{3}{*}{ Agrigento } & ERS1/2 & D & $11 / 11 / 1992-23 / 12 / 2000$ \\
\cline { 2 - 4 } & ENVISAT & A & $16 / 11 / 2002-17 / 07 / 2010$ \\
\cline { 2 - 4 } & ENVISAT & D & $05 / 06 / 2003-18 / 02 / 2010$ \\
\hline
\end{tabular}




\section{DISCUSSION}

\section{Feasibility of PSI measures on cultural heritage}

Successful implementation of PSI techniques for analyses on sites with ruins and monuments mainly depends on the availability of sufficient PS density over the study area, detected through the multi-interferogram processing of SAR images. Highly vegetated sites and cultural heritage, partially or totally hidden by wooded coverage, can be monitored hardly, since vegetation prevents the recognition of PS on ground. On the other side, archaeological structures and buildings located in open areas or emerging from forested surroundings can generate PS, useful to carry out deformation analyses. To this purpose, the case of the $17^{\text {th }}$-century Sanctuary of St. Rosalia in Palermo, Sicily, is quite demonstrative (figure 2A). The building, sacred thanks to the St. Rosalia's relics there preserved, was built within a narrow ravine of the rock mass at the top of Mount Pellegrino. Although the surrounding densely vegetated areas do not provide any PS, they contribute to emphasize the availability of PS in correspondence to the historical structures, as found after the processing of ENVISAT descending data stack (figure 2A). The orientation of the Sanctuary and the satellite acquisition geometry led to the identification of PS in the study area; such sort of evidence confirms the potentials of PSI for applications on archaeological complexes sited in forested areas or wetlands (e.g., Maya temples in Mexico, Angkor monuments in Cambodia).
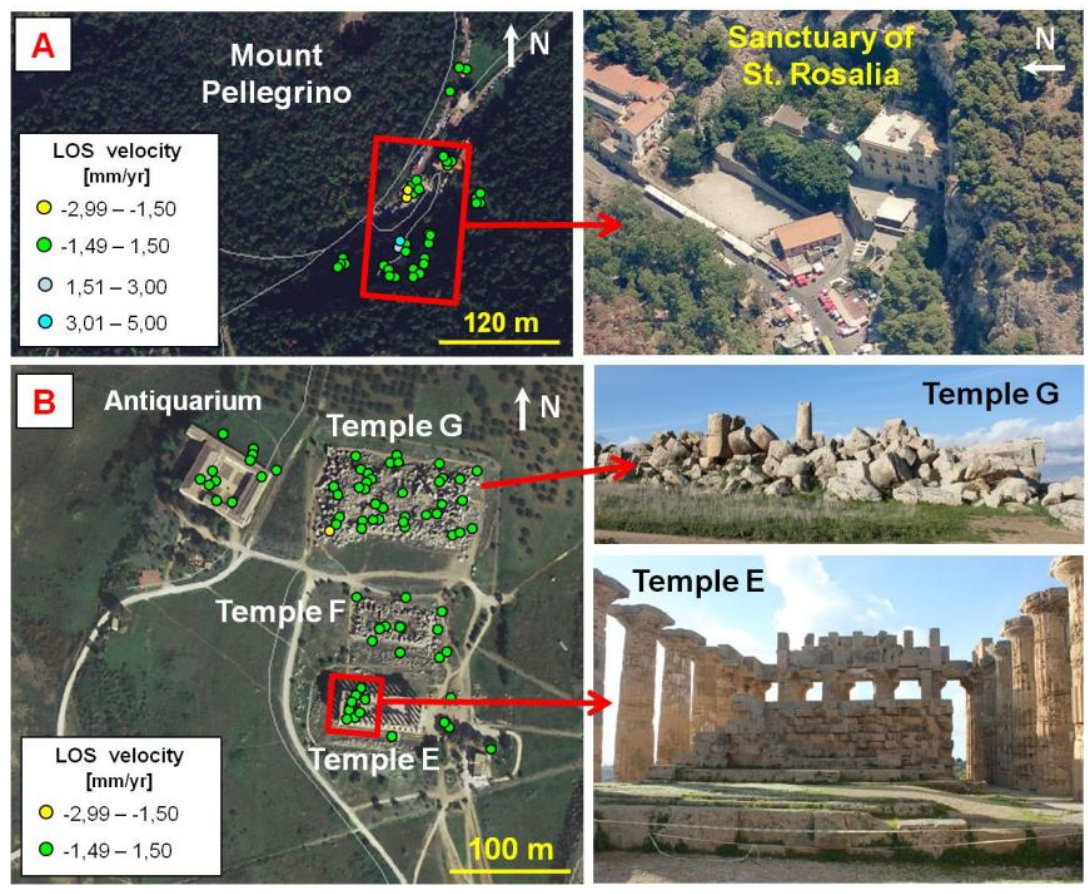

Figure 2. A) PS LOS velocities in the area of St. Rosalia's Sanctuary in Palermo, Sicily, obtained from ENVISAT descending data acquired in November 2002 - October 2010. PS concentrate on the buildings of the Sanctuary. B) PS LOS velocities in the eastern sector of Selinunte, Sicily, obtained from ENVISAT descending data covering the period March 2003 June 2010. PS are detected in correspondence to both columns drums and standing structures (PSI data in A and B are based on EPRS-E, 2011). 
A technical encouragement to test PSI techniques on cultural heritage derives from the typical feature characterizing most archaeological sites, i.e. the presence of ruins and architectural elements (columns, drums, pillars, foundations, wall masonries) emerging from the ground, or even entire structures well preserved in their whole integrity, or reconstructed by archaeologists adopting anastylosis methods. That is the case of archaeological areas like Selinunte, Southwestern Sicily, for which the processing of ENVISAT images resulted in a high density of PS concentrated over the eastern sector of the site, with displacement measures available for both reconstructed (Temple E) and ruined (Temples G and F) structures (figure 2B).

\section{Detection of deformation patterns}

One of the most promising perspectives in the use of PSI for deterioration studies is offered by the capability to detect instability processes at 'site scale', allowing the estimation of the magnitude of the observed phenomenon, as well as the characterization of its spatial distribution. The latter parameter plays a fundamental role in the evaluation of the typology of ongoing phenomena, whose intensity can be the same over the entire site, or show a differential behavior. Structural deterioration of archaeological remains is frequently caused by instability of the geologic substratum. The recognition of deformation patterns associable to active natural and/or human-induced processes can clarify the susceptibility of cultural heritage to potential damages, and support a better planning of necessary stabilization interventions.

A deformation pattern is clearly identified whenever the spatial distribution of PS marks an area with homogeneous values of LOS deformation rates and/or the single PS deformation time series display common acceleration/deceleration phases or significant changes in displacement trend. Negative values of LOS deformation rates are generally linked to subsidence/collapse/soil compaction, while positive values are associable to a variety of uplift motions, spanning from volcanic activity to groundwater recharge and clayey soil expansion. In terms of extent, a deformation pattern can range from tens of square meters to hundreds of square kilometers. While macro-patterns usually reveal active phenomena at regional scale, micro-patterns can highlight conservation criticalities on single portions of a sector or monument, presumably in correspondence to structural weakness points, more deteriorated architectural elements, or structures founded on unstable ground. Non-homogeneous distribution of LOS deformation rates over the interest area can be a reliable evidence of differential response to the same phenomenon, or the coexistence of different phenomena within the same area.

\section{$\underline{\text { Subsidence and cliff instability in Capo Colonna, Central Calabria }}$}

The archaeological site of Capo Colonna occupies the head of a promontory overlooking the Ionian Sea, SE of Crotone, and derives its name from the columns of the Greek temple dedicated to the goddess Hera (figure 3). It formerly constituted the landmark for ancient sailors, but nowadays a unique column still remains on site, after centuries of repeated robbing of building materials. The Column, carved in the local calcarenite and founded on a thick sandstone base, is located at the margin of a composite terrace, very close to the rock cliffs, at about $15 \mathrm{~m}$ a.s.l.

The local geologic stratigraphy shows clay bedrock (pelite) outcropping in the southern part of the promontory and constituting the submerged coastal platform. It is overlain by a sequence of calcareous sandstones, with different grade of cementation and intense fracture pattern in the 
upper part. The constant action of sea erosion undermines the cliff and generates rockfalls and collapses, with a total retreat of $150 \mathrm{~m}$ in the last 110 years for the north-eastern tip [8]. Here, the ruins of the ancient Roman settlement are perilously distributed along the cliff edge, directly facing the sea, with high susceptibility to masonry collapses and toppling in consequence of rockfalls. Further geohazard for the preservation of the archaeological remains is represented by the subsidence that historically affects the entire promontory. Scientists recognized the origin of such phenomenon in a combination of natural processes (e.g., lithostratigraphic setting, seismic activity and eustatic sea-level changes) and hydrocarbons extraction [9]. A wide-area worsening of the substratum instability might develop in the near future, as well as local destabilization of the standing structures.

The PSInSAR analysis performed on historical data acquired from the satellites ERS confirms an active subsidence over the whole promontory (figure 3). A huge area characterized by homogeneous deformation pattern with displacements away from the satellite can be identified in the descending data stack in June 1992 - December 2000 (figure 3A). Average LOS velocity of $-6 \mathrm{~mm} / \mathrm{yr}$ and a definite trend away from the satellite are measured since May 1995 for PS distributed within the archaeological site. Going westward inland, LOS velocities tend to increase, reaching values up to $-10 \mathrm{~mm} / \mathrm{yr}$. Comparison of PS distribution with lithological and marine terraces maps highlights that the subsidence macro-pattern is mainly concentrated in the correspondence to the calcareous terrace, which constitutes the foundation of the archaeological structures. A drastic change in LOS displacement rates is identified W of the terrace. Such evidence suggests a correlation between local geologic setting and the measured displacements.

Subsidence remains active even after 2000, as observed from the PSP-DIFSAR analysis of the ENVISAT ascending data stack (2003-2010) (figure 3B). The spatial distribution of the LOS velocities shows higher values in the central part of the promontory than the coastal area, with values ranging from -5 to $-13 \mathrm{~mm} / \mathrm{yr}$. Hence, contribution from local groundwater pumping, which overlaps with the effects of local geology, cannot be excluded. As observed in the ERS1/2 descending data (1992-2000), the subsidence pattern follows the extent of the calcareous terrace, with significant values of LOS displacements away from satellite distributed westward inland.

Focusing on the archaeological area, three localized micro-patterns were identified on the following sectors: 1) Column and Temple A; 2) balneum and building M; 3) Capo Nao Tower and St. Mary Sanctuary (figure 3C). Within the sector 1, the Column and the surrounding basement show displacements with average LOS deformation rate of $-4.8 \mathrm{~mm} / \mathrm{yr}$ and two different accelerations recognizable within the PS time series, respectively, in the periods June 2004 - August 2005 and June 2008 - March 2009. Similar acceleration phases characterize PS distributed on the nearby foundations of the Temple A. Localized displacements interest both the ruins and ground at the SW corner of the balneum and building $\mathrm{M}$ area (sector 2), with average LOS velocity of $-5.6 \mathrm{~mm} / \mathrm{yr}$ and same changes in displacement trend as those in the PS time series identified on the architectural structures of Capo Nao Tower and the church (sector 3). Movements away from the satellite, with LOS velocity up to $-4.3 \mathrm{~mm} / \mathrm{yr}$, were detected along the rock cliff. These displacements can be reasonably attributed to a combination of subsidence and rock slope instability. The cliff is extensively fractured in different blocks prone to falling down into the sea, with potential impacts on the structures dangerously located along the cliff edge.

The conservation criticalities discovered for the sectors 1 and 3 agree with risk mapping reported in the Hydrogeological Setting Plan for Capo Colonna promontory, which classifies them as landslide-prone areas. Furthermore, the evidence of subsidence achieved from the radarinterpretation of two data stacks different in exploited satellites, monitoring periods and 
processing approaches adopted, confirms the persistence of deformation at least since 1992 over the entire archaeological area, and more generally over the promontory, with significant worsening at regional scale, from historical data to more recent measures.
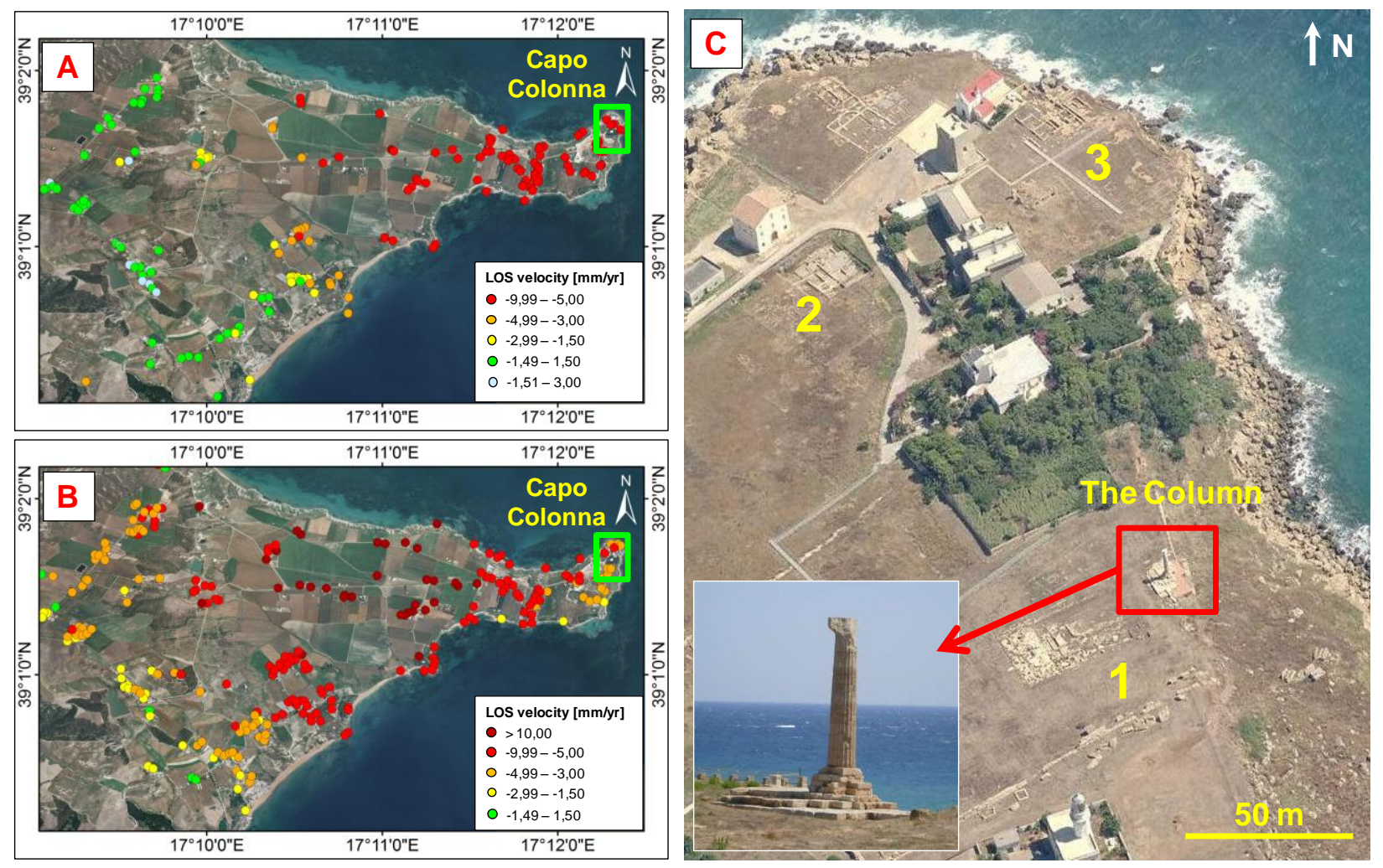

Figure 3. Subsidence macro-pattern detected over Capo Colonna promontory: A) ERS descending data (1992-2000); B) ENVISAT ascending data (2003-2010). Deformation affects the archaeological ruins in the sector: 1. Column and Temple A; 2. balneum and building M; 3. Capo Nao Tower and St. Mary Sanctuary (PSI data in A and B are based on EPRS-E, 2011).

\section{Deformation patterns due to volcanic bradyseism in Pozzuoli, W of Naples}

The historic centre of Pozzuoli, formerly the Roman town of Puteoli, is located W of Naples, along the coast of the homonymous bay, within the Campi Flegrei area. The latter is an active volcanic caldera, produced during the eruption of the Neapolitan Yellow Tuff (about 15,000 years BP). The entire area is subjected to bradyseism, i.e. gradual uplift/descent vertical movements as effects of filling/emptying of underground magma chamber and/or thermal activity, quite common in volcanic calderas. A long history of local ground elevation changes is recorded, with uplifts having frequently preceded eruptions, as occurred before the event that formed the scoria cone of Monte Nuovo in 1538.

Effects of historical bradyseism are also recognized on the archaeological heritage of Pozzuoli, like the marine burrowing mollusks found up to about $7 \mathrm{~m}$ above present sea level on the three marble columns of the Roman marketplace (Macellum or Serapaeum) and selected by scientists as biological sea level indicators. Analysis of old photographs allowed an estimation of the progressive sinking that interested the columns and the surrounding remains until 1950, with 
the occurrence of a major uplift in the period 1950-1952 [10]. Attention of local administrators for potential impacts on monuments and public safety is testified by the forced evacuation in 1970 of the entire Rione Terra, the southern historical quarter of Pozzuoli.

Focusing on the last thirty years of bradyseism at Pozzuoli, the Campi Flegrei area was affected by a gradual slow subsidence in 1984-2006, temporarily interrupted by mini-uplift events and modest seismic activity in 1989 and 1999-2000. Nevertheless, recent geodetic measurements suggest a significant inversion of the displacement trend. Uplift movements were measured in November 2004 - November 2006, with a low but increasing rate leading to about $40 \mathrm{~cm}$ of uplift till the end of October 2006 [11].

A satellite confirmation for such sequence of differential bradyseismic phases was retrieved from the comparison between ERS descending (1992-2000) and ENVISAT ascending (20022008) data stacks processed for the entire area of Campi Flegrei, jointly with a detailed analysis of PS time series identified in the correspondence to archaeological structures (figure 4). ERS data clearly show sub-circular banded subsidence pattern within the Neapolitan Yellow Tuff caldera, centered on Pozzuoli (figure 4A). Here, PS velocities reach the highest values, with average LOS velocity more than $-30 \mathrm{~mm} / \mathrm{yr}$ away from the satellite. PS time series for Serapaeum and Roman amphitheatre display a constant subsidence trend in the period June 1992 - October 1999 with LOS velocity of $-27 \mathrm{~mm} / \mathrm{yr}$ and $-29 \mathrm{~mm} / \mathrm{yr}$, respectively. An inversion of the trend started in December 1999, with average LOS velocity for the two archaeological monuments of about $31 \mathrm{~mm} / \mathrm{yr}$ and $36 \mathrm{~mm} / \mathrm{yr}$ towards the satellite (figure 4B). The presence of similar displacement trends in the PS time series over the Rione Terra defines a deformation pattern spatially extended to the whole town centre, in agreement with geodetic measurements.
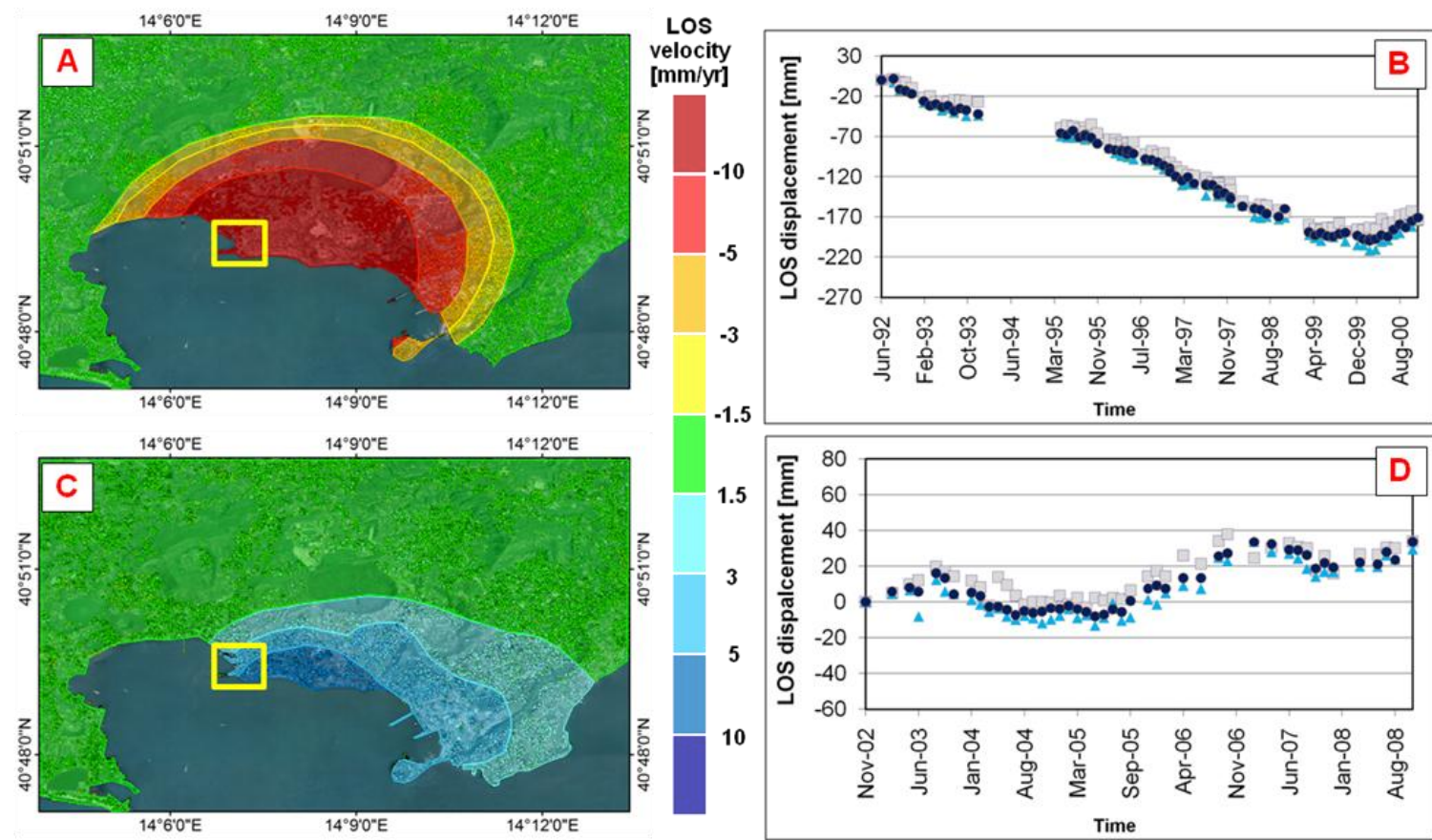

Figure 4. Deformation patterns detected over the Campi Flegrei area and Pozzuoli (the yellow box marks the historic town centre): A) subsidence in ERS descending data (1992-2000); C) uplift in ENVISAT ascending data (2002-2008); with related PS time series (B-D). PSI data are based on EPRS-E (2011). 
A confirmation to the uplift phase detected after 2004 is found from the spatial distribution of ENVISAT ascending data (2002-2008) (figure 4C). Ground motions result completely inverted all over the study area, with definite uplift deformation pattern on Pozzuoli and highest values of LOS velocity up to $7 \mathrm{~mm} / \mathrm{yr}$ towards the satellite for PS identified over the Rione Terra. Uplift also affects the eastern coast of the bay. Differently from the subsidence trend occurred in 19921999, PS time series do not show constant uplift trend in 2002-2008. Detailed temporal analysis of PS for Serapaeum, Roman amphitheatre and Rione Terra highlights three major uplift phases, respectively, in the periods November 2002 - August 2003, June 2005 - January 2007, and March 2008 - October 2008 (figure 4D). Such phases were only temporarily interrupted by deceleration phases, with relative stabilization or even the occurrence of displacements away from the satellite. In correspondence to the archaeological monuments, the highest LOS velocities are observed during the second uplift phase, reaching values of $37 \mathrm{~mm} / \mathrm{yr}$.

Although both the subsidence and uplift patterns detected in Pozzuoli do not configure differential displacements for the foundation ground of the archaeological monuments, they undoubtedly confirm the critical exposure of the local cultural heritage to sequences of different terrain motions that could induce structural stresses on the masonries, causing progressive destabilization and/or loss of verticality (especially for linear architectural elements like columns and pillars), or even localized collapses.

\section{PS time series analysis on the Valley of the Temples, Agrigento}

The Valley of the Temples, located S of the modern town of Agrigento, Sicily, is listed in the World Heritage List of UNESCO because of its archaeological heritage, extraordinarily preserved from the Greek and Roman periods. Eight monumental temples, partially or totally recomposed by the archaeologists, were built between the $6^{\text {th }}$ and $5^{\text {th }}$ centuries BC along the edge of a hill, purposely chosen as natural buttress against external attacks. The defense walls were directly carved in the rock mass along the edge, as still appreciable walking from the Temple of Hera Lacinia to the Temple of Concord.

The geologic setting of the area is characterized by an asymmetrical syncline with E-W axis, whose core consists of an alternation of biocalcarenite and biocalcirudite, marly sand and clayeysandy silt (Agrigento formation; Lower Pleistocene) lying discontinuously on blue-grey siltymarly clays (Mt. Narbone formation; Middle-Upper Pliocene) [12]. Low quality and high fracturing of biocalcarenite, rheological contrast between calcarenite (brittle) and underlying silts and clays (plastic), combined with erosion, make the entire relief prone to slope instability, contributing to trigger local rock-slumps, topples and/or slides, with high probability of direct impacts on the archaeological heritage. On-site inspections led to discover diffuse presence of large sized fallen blocks along the slope, such as beneath the Temple of Hera Lacinia, where debris of past collapses progressively accumulated. In 1976 a landslide occurred at the eastern margin of the site, blocking temporarily the access to the Valley and damaging the Temple of Hera Lacinia. Additional factors predisposing structural instability have to be identified in the properties of the local biocalcarenite employed to build the temples, and related deterioration processes, among which the undermining due to differential erosion.

The impression that the site is interested by different localized criticalities, rather than a unique instability phenomenon, was confirmed by site-specific analysis of both historical and recent satellite data covering the period 1992-2010. The spatial distribution of LOS deformation 
rates does not configure any pattern associable to wide-area active phenomena, but highlights single areas with ongoing displacements that might evolve in future damages. In such cases detailed analysis of PS time series represents the most effective approach to distinguish unstable from stable sectors and achieve an up-to-date mapping of conservation criticalities to be verified directly on site [13]. Furthermore, PS that are apparently classifiable as 'stable' due to their low values of average LOS velocity, can actually show a time series characterized by sequence of acceleration/deceleration phases that, during the averaging over the entire monitoring period, results in an overall relative stability. Peculiar behavior of construction materials and terrain can also be observed.

Analyzing ERS descending data (1992-2000), two apparently 'stable' PS, found in correspondence to the architectural elements of the Temple of Concord, show similar displacement trend with a seasonal component and a slight tendency to movement towards the satellite, with average LOS velocity up to $1.3 \mathrm{~mm} / \mathrm{yr}$, period of 1 year and amplitude of $5 \mathrm{~mm}$. Something similar is observed for three PS identified on the terrain in front of the eastern façade of the Temple of Heracles, with average LOS velocity up to $1.2 \mathrm{~mm} / \mathrm{yr}$ (figure 5A). On the other hand, for the PS located SW of the temple the seasonal component of the displacements configures a constant trend away from the satellite, with LOS deformation rate of $-5.1 \mathrm{~mm} / \mathrm{yr}$.

Movements with opposite direction and average LOS velocity of $2.4 \mathrm{~mm} / \mathrm{yr}$ are observed in 1992-2000 close to the standing columns of the Temple of Castor and Pollux, within an almost stable area, suggesting the presence of localized instability. A confirmation is found with the ENVISAT ascending data (2002-2010), that detect two PS at the SE corner of the temple, with LOS velocities of $-2.8 \mathrm{~mm} / \mathrm{yr}$ away from the satellite and $1.8 \mathrm{~mm} / \mathrm{yr}$ towards the satellite, respectively.

Based on the ENVISAT ascending data, some conservation criticalities are also detected for other temples. In the area facing the eastern façade of the Temple of Hera Lacinia, one PS suggests the presence of progressive movements away from the satellite, with average LOS velocity of $-1.2 \mathrm{~mm} / \mathrm{yr}$ in 2002-2010, which may be followed by a further worsening. These movements seem reasonably attributable to local ground instability. On the other hand, the displacements with average LOS velocity of $-2.2 \mathrm{~mm} / \mathrm{yr}$ away from the satellite, measured in correspondence to the standing stone masonry at the pronaos of the Temple of Olympian Zeus, suggest considering them as effects of ongoing structural criticality.

In relation to rock toppling/fall hazard along the cliff edge, a PS with significant deformation trend away from the satellite is found in the ENVISAT descending data stack, in correspondence to boulders highly fractured and toppled along the cliff edge, SW of the Temple of Concord (figure 5B). The average LOS velocity of $-4.1 \mathrm{~mm} / \mathrm{yr}$ calculated in the period June $2003-$ September 2008 confirms the high susceptibility of the entire sector, where several toppling events occurred and underwalls were built to prevent further block detachments.

Potentials of PSI techniques to early stage warning of triggering/reactivation of such phenomena is demonstrated by the detection of unexpected movements on an apparently 'stable' sector of the cliff edge, along the walkway towards the Temple of Concord. Although the average LOS velocity is quite low, one PS shows an acceleration phase since August 2008, assumable as precursor signal of a probable block detachment. 

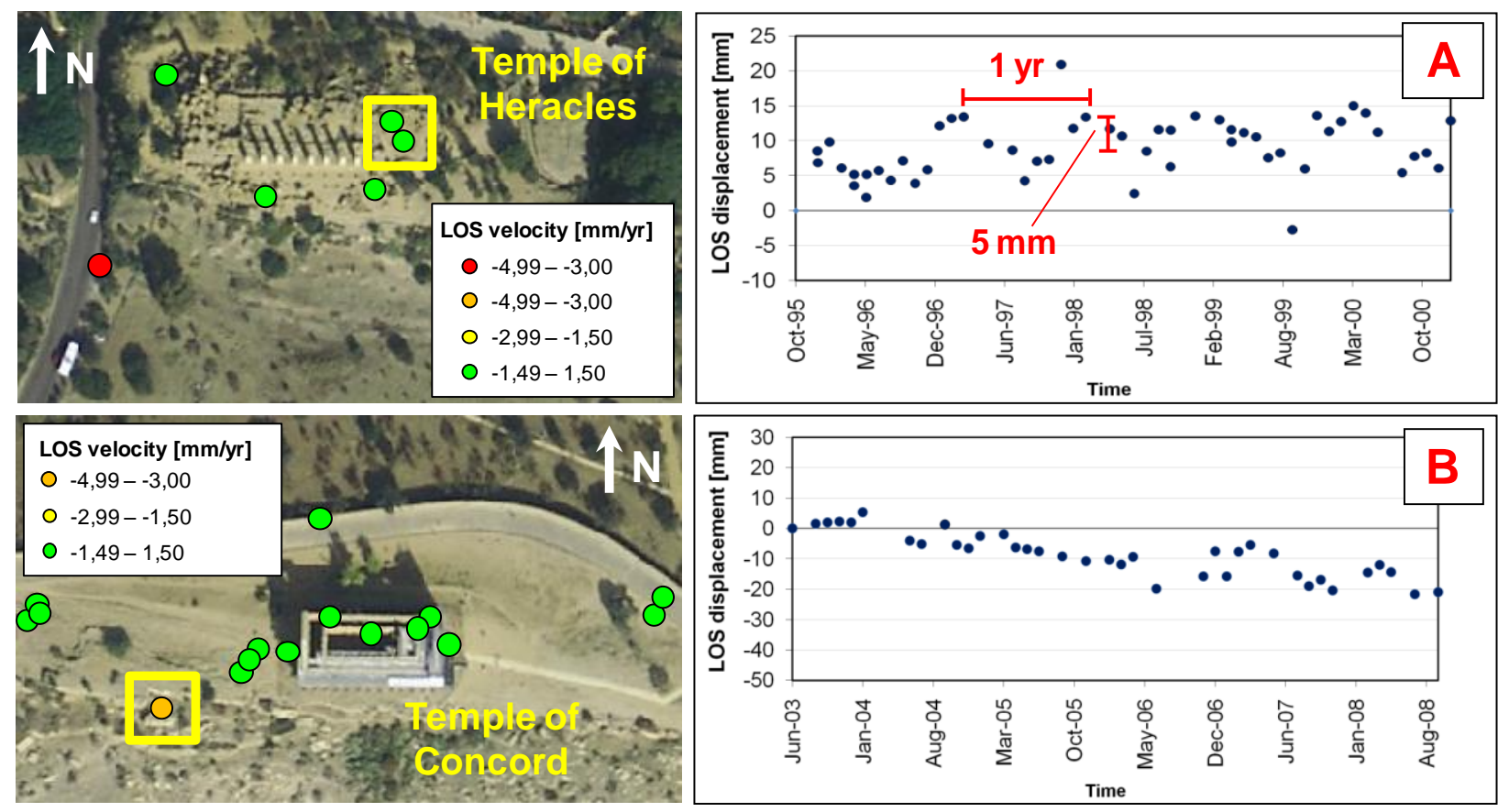

Figure 5. A) PS LOS velocities in the area of the Temple of Heracles, obtained from ERS descending data (1992-2000). Seasonal component with $5 \mathrm{~mm}$ of amplitude is detected within the PS time series. B) PS LOS velocities for the Temple of Concord, obtained from ENVISAT ascending data (2003-2010). One PS with constant trend away from the satellite is detected in correspondence to the cliff edge (PSI data in A and B are based on EPRS-E, 2011).

\section{CONCLUSIONS}

Satellite interferometric data from the Extraordinary Plan of Environmental Remote Sensing were explored on three cultural heritage sites in Southern Italy to detect ground and structural deformation patterns, and clarify the nature of past/active deterioration phenomena. Site-specific analyses performed on Capo Colonna and Pozzuoli proved the suitability of InSAR techniques to identify wide-area deformation phenomena with direct impact on archaeological monuments. Recognition of localized conservation criticalities over the Valley of the Temples in Agrigento was achieved through detailed analysis of PS time series, discriminating different deformation behaviors and identifying unstable sectors where further investigations and/or interventions might be planned.

\section{ACKNOWLEDGMENTS}

PSI data of the Extraordinary Plan of Environmental Remote Sensing (EPRS-E) were made available through the freely accessible WMS service of the National Geoportal of the Italian Ministry of Environment, Territory and Sea (METS). 


\section{REFERENCES}

1. D. Tapete, N. Casagli, R. Fanti, C. Del Ventisette, R. Cecchi, P. Petrangeli, Geophysical Research Abstracts Vol. 13, EGU2011-8387 (2011).

2. N. Casagli, R. Cecchi, D. Tapete, P. Petrangeli, R. Fanti, C. Del Ventisette in Scienza e Beni Culturali XXVII. 2011 Governare l'innovazione, edited by G. Biscontin and G. Driussi (Edizioni Arcadia Ricerche, Marghera-Venezia, 2011), pp. 323-331 and table 6.

3. D. Massonnet and K.L. Feigl, Rev. Geophys. 36, 441-500 (1998).

4. E. Cabral-Cano, A. Arciniega-Ceballos, O. Díaz-Molina, F. Cigna, B. Osmanoğlu, T. Dixon, C. DeMets, F. Vergara-Huerta, V.H. Garduño-Monroy, J.A. Ávila-Olivera, E. Hernández-Quintero in Land subsidence, associated hazards and the role of natural resources development, edited by D. Carreón-Freyre et al. (Hydrological Sciences Journal, Red Book Series. IAHS Press, Wallingford, UK, 2010), pp. 164-169.

5. P.A. Rosen, S. Hensley, I.R. Joughin, F.K. Li, S.N. Madsen, E. Rodriguez, R.M. Goldstein, Proc. I.E.E.E. 88 (3), 333-382 (2000).

6. M. Costantini, A. Iodice, L. Magnapane, L. Pietranera, Proc IGARSS, 3225-3227 (2000).

7. A. Ferretti, C. Prati, F. Rocca, IEEE T. Geosci. Remote 39 (1), 8-20 (2001).

8. U. Chiocchini, in Geological and Geotechnical influences in the Preservation of Historical and Cultural Heritage, edited by G. Lollino (GNDCI - CNR, n. 2133, Turin, 2000), pp. 389-396.

9. F. Verdecchia, C. Zoccatelli, E. Norelli, R. Miandro, in Land subsidence, associated hazards and the role of natural resources development, edited by D. Carreón-Freyre et al. (Hydrological Sciences Journal, Red Book Series. IAHS Press, Wallingford, UK, 2010), pp. 345-351.

10. C. Del Gaudio, I. Aquino, G.P. Ricciardi, C. Ricco, R. Scandone, J. Volcanol. Geotherm. Res. 195, 48-56 (2010).

11. C. Troise, G. De Natale, F. Pingue, F. Obrizzo, P. De Martino, U. Tammaro, E. Boschi, Geophys. Res. Lett. 34, L03301 (2007).

12. V. Cotecchia, F. Fiorillo, L. Monterisi, R. Pagliarulo, Giornale di Geologia Applicata 1, 91-101 (2005).

13. F. Cigna, C. Del Ventisette, V. Liguori, N. Casagli, Nat. Hazards Earth Syst. Sci. 11, 865-881 (2011). 